\title{
BMJ Open Influence of psychological factors on the prognosis of chronic shoulder pain: protocol for a prospective cohort study
}

\author{
Javier Martinez-Calderon, ${ }^{1}$ Filip Struyf, ${ }^{2}$ Mira Meeus, ${ }^{2,3,4}$ \\ Jose Miguel Morales-Ascencio, ${ }^{5}$ Alejandro Luque-Suarez ${ }^{1}$
}

To cite: Martinez-Calderon J, Struyf $\mathrm{F}$, Meeus M, et al. Influence of psychological factors on the prognosis of chronic shoulder pain: protocol for a prospective cohort study. BMJ Open 2017;7:e012822.

doi:10.1136/bmjopen-2016012822

- Prepublication history for this paper is available online. To view these files please visit the journal online (http://dx.doi.org/10.1136/ bmjopen-2016-012822).

Received 26 May 2016 Revised 25 January 2017 Accepted 2 February 2017

CrossMark

For numbered affiliations see end of article.

Correspondence to Dr Alejandro Luque-Suarez; aluques@uma.es

\section{ABSTRACT}

Introduction: Shoulder pain is a highly prevalent condition. Psychological factors could play an essential role in the prognosis of chronic shoulder pain (CSP). The aims of the study will be to analyse the level of association between psychological factors and pain-disability at baseline and prospectively to assess their prognostic role; to evaluate the association of pain catastrophising and kinesiophobia at baseline and prospectively in the relationship between pain intensity and disability, or between selfefficacy and disability in patients with CSP; to explore the association of self-efficacy at baseline and prospectively in the relationship between pain intensity and disability, in comparison with kinesiophobia and pain catastrophising.

Methods and analysis: The study is a longitudinal, prospective cohort study with a 12-month follow-up. It will be conducted in 4 primary-care centres and one hospital of the province of Malaga, Spain. 307 participants aged between 18 and 70 years suffering from CSP (3 months or more) will be included. Primary outcomes will include pain, disability and self-efficacy, whereas kinesiophobia, pain-related fear, pain catastrophising, anxiety, depression, patient expectations of recovery, age, gender, duration/intensity of symptoms, educational level and other factors will be predictive measures. Follow-up: baseline, 3,6 and 12 months.

Ethics and dissemination: The local ethics committee (The Costa del Sol Ethics Committee, Malaga, 28042016) has approved this protocol. Dissemination will occur through presentations at National and International conferences and publications in international peer-reviewed journals. Trial registration number: NCT02738372; preresults

\section{INTRODUCTION}

Shoulder pain is the third most common musculoskeletal condition presenting to physicians or physiotherapists ${ }^{1}$ in primary healthcare after low back and neck pain, ${ }^{23}$ being a significant cause of morbidity, ${ }^{4}$ and

\section{Strengths and limitations of this study}

- The inclusion of a long battery of psychological factors evaluating their role in the prognosis of chronic shoulder pain.

- The exploration of the mediating power of selfefficacy, kinesiophobia and pain catastrophising in chronic shoulder pain.

- The inclusion of self-efficacy as an outcome measure.

- Some psychological factors such as pain acceptance and psychological distress will be not included in this study.

- Another limitation could be that some psychological factors are quite broad in definition, increasing the risk on finding conflicting evidence on their relationship with outcomes.

functional disability in both working ${ }^{5}{ }^{6}$ and general population. ${ }^{6-8}$ It affects one in three adults, ${ }^{79} 10$ accounting $1 \%$ of general practitioners' (GPs) consultations in primary care. $^{11}$

Incidence rates range from 11.2 to 29.5 per 1000 person-years, ${ }^{11-14}$ and the reported prevalence rates range from 4.7 to 46.7 per 1000 person-years. ${ }^{10} 14 \quad 15$ Incidence and prevalence rates tend to increase with age, ${ }^{16}$ in women, ${ }^{10} 16^{17}$ in persons from lower socioeconomic groups, and in psychologically stressed populations. ${ }^{18}$

Despite the large group of individuals seeking for primary-care services, about $50 \%$ of patients with shoulder pain still report persistent pain after 12 months. ${ }^{9} 16 \quad 1819$ As a result, socioeconomic burdens are considerable due to extensive use of heath care services, sickness absence, disability pension and loss of productivity, ${ }^{20-24}$ as well as patient's suffering.

That is why there is a consensus in the field that research efforts need to be focused on obtaining insight into which prognostic factors play the most important roles in 
chronic shoulder pain (CSP), and how those factors impact on pain and function, as this understanding is crucial to acquire a clear comprehension of all the process involved in CSP and to underline pain-treatment effects in seeking to improve the poor prognosis of this entity.

CSP is a complex syndrome, and pain chronicity often cannot be explained (solely) by an obvious anatomic defect or tissue damage. ${ }^{25}$ A recent review ${ }^{26}$ exposed that the effective management of shoulder pain relies on a detailed knowledge of peripheral pathology (ie, adhesive capsulitis, SLAP lesion or rotator cuff tendinopathy), as well as on a comprehensive understanding of how pain can be generated, propagated and modified. In this sense, there has been a growing recognition that the degree of chronic pain is influenced by the beliefs, attitudes and expectations of individuals. ${ }^{27-29}$ Given the importance of pain as a mechanism of survival, it is perhaps unsurprising that pain perception is clearly influenced by conscious and unconscious memory, cognitive and emotional functioning and contextual factors that are explicitly included in a biopsychosocial formulation of pain. $^{30}$ Inside of the biopsychosocial understanding of chronic pain, there is a growing interest, and acceptance in hypothesising that the association between physical impairment, pain intensity and pain-related disability is only moderate and that psychological factors may influence the experience of pain and its impact and hence may play a crucial role in the maintenance of pain-related problems. $^{27} 31$ Currently, some evidence has shown how psychological factors could be associated with the prognosis of CSP. ${ }^{32-}$ ${ }^{34}$ Reilingh $e t a l^{32}$ investigated the course and prognosis of shoulder pain in the 6 first months after presentation to the GP. Predictors of a better outcome for CSP were lower scores on pain catastrophising and higher baseline pain intensity (explained variance 21\%). Gill et $a l^{33}$ examined which factors are predictive of incident, recurrent or resolved shoulder pain in a community-based sample from the general population. Findings showed how recurrent shoulder pain was associated with depressive symptoms. Chester $e t a l^{34}$ aimed to identify which baseline patient and clinical characteristics are associated with a better outcome, 6 weeks and 6 months after starting a course of physiotherapy for shoulder pain. In this study, higher patient expectation of complete recovery compared to slight improvement because of physiotherapy and higher pain self-efficacy were associated with patient-rated outcomes.

Therefore, it seems presumable that psychological factors could play a role in people with shoulder pain and favour the perpetuation of CSP. Self-efficacy has been proposed to predict pain, pain behaviour, physical functioning and disability in chronic musculoskeletal pain. ${ }^{35}{ }^{36}$ Furthermore, self-efficacy is considered to be a stronger mediator of the relationship between pain behaviour, pain intensity and disability than psychological factors such as kinesiophobia and pain catastrophising. ${ }^{37-39}$ However, the role of self-efficacy as an outcome measure and as mediator in CSP has not been studied yet. Knowing and understanding which psychological factors are specifically involved in the prognosis of CSP is challenging to facilitate clinical decision-making and, if necessary, timely, and specific consultation with-or referral to-other healthcare providers. $^{40}$

There are four hypotheses in the present study. First, higher levels of psychological factors at baseline and prospectively such as kinesiophobia, pain-related fear, depression, anxiety, patient expectations of recovery and pain catastrophising are associated with a higher level of pain intensity, and disability, and lower level of selfefficacy. Second, pain catastrophising and/or kinesiophobia mediate the relationship between pain intensity and disability, or between self-efficacy and disability at baseline. Third, changes in pain catastrophising and/or changes in kinesiophobia mediate the relationship between changes in pain intensity and changes in disability, or changes in self-efficacy and changes in disability after 12 month follow-ups. Fourth, self-efficacy is the strongest mediator in the relationship between pain intensity and disability at baseline and prospectively. Hence, the aims of the present study will be: (1) to analyse the level of association between psychological factors and pain-disability at baseline and prospectively to assess their prognostic role; (2) to evaluate the association of pain catastrophising and kinesiophobia at baseline and prospectively in the relationship between pain intensity and disability or between self-efficacy and disability in patients with CSP; (3) to explore the association of self-efficacy at baseline and prospectively in the relationship between pain intensity and disability, in comparison with kinesiophobia and pain catastrophising.

\section{METHODS AND ANALYSIS}

\section{Study design and setting}

The present study will be a 12 month multicentre, prospective, cohort study that will be carried out between May 2016 and April 2017 in four primary-care centres and one hospital of the province of Malaga, Spain. Several questionnaires assessing different psychological factors will be administrated to these participants. The outcomes will be assessed at baseline (t1) and at 3 follow-ups times (after 3 (t2), 6 (t3) and 12 months (t4)). Ethical approval has been obtained from Costal del Sol Ethics Committee, Malaga, Spain (28042016). The study will be implemented and reported in line with the SPIRIT statement.

\section{Participants}

A consecutive sample comprised participants with CSP will be recruited. GPs will carry out the recruitment. Then, the research assistants who will be previously instructed by the research team will assess the 
participants for eligibility. If the participants satisfy the eligibility criteria, they will be invited to participate in this study, and then they will be evaluated at baseline and 3, 6 and 12 months' follow-up. The inclusion criteria as follows: (1) men/women aged over 18 years and (2) participants suffering from shoulder pain (pain intensity of 3 or more on a $0-10$ numerical pain rating scale) will be included in this study, among all these following shoulder pain conditions: non-specific shoulder pain, subacromial pain syndrome, rotator cuff tendinopathy, adhesive capsulitis, instability without trauma, SLAP lesion, acromioclavicular pathology and/or shoulder osteoarthritis. Diagnosis will be carried out by clinical testing based on the recommendations of McClure et $a l,{ }^{41}$ and radiological test through MRI and/or ultrasound imaging; (3) duration of symptoms: more than 3 months. The exclusion criteria as follows: (1) recent shoulder dislocation (1 year prior) and/or systemic diseases such as rheumatoid arthritis, fibromyalgia and/or polymyalgia rheumatic; (2) shoulder pain considered to be originated from the cervical region, and other traumas, or if there is a neurological dysfunction (ie, multiple sclerosis or stroke), osteoporosis, haemophilia and/or cancer; (3) participants receiving shoulder surgery; (4) participants with shoulder pain after post fracture; and (5) inability to provide informed consent and/or complete written questionnaires.

\section{Procedures}

Recruitment

Anonymised age and gender details will be collected for those participants who decline to take part in the project, to assess the external validity of the recruited sample of participants.

Eligible participants who will be interested in the study will be asked to provide written informed consent to participate. Participants will then complete several questionnaires at baseline, 3, 6 and 12 months after the beginning of the study.

Participant data files will be stored in numerical order and in a secure and accessible place and manner. Participant files will be maintained in storage for a period of 3 years after completion of the study.

\section{Outcomes measures}

Outcome measures and some of the potential prognostic factors will be measured at baseline and prospectively, with the aim of observing possible associations between potential prognostic factors and pain disability, and self-efficacy at baseline, and prospectively to assess their prognostic role, and if some of them appear as confounding factors.

\section{Primary outcome}

Pain and function

1. The Shoulder Pain and Disability Index (SPADI) is a self-administered index consisting of 13 items divided into two subscales: pain and disability. ${ }^{42}$ It grades a normal shoulder as 0 and maximally affected as 130 , and an 11-point numerical pain rating scale with 0 as normal and 10 as maximal pain.

\section{Secondary outcome}

\section{Self-efficacy}

2. Pain Self-Efficacy Questionnaire (PSEQ) contains 10 questions that will measure the patient's confidence in performing certain activities despite pain. Items are scored on a scale from 0 to 6 , with a maximum possible score of 60 points. Lower scores indicate less self-efficacy. ${ }^{43}$

\section{Potential prognostic factors}

Psychological factors will be assessed through four questionnaires at baseline, 3, 6 and 12 months follow-up.

\section{Kinesiophobia, pain-related fear, pain catastrophising,} anxiety, depression and patient expectations of recovery

1. The Fear-avoidance Components Scale (FACS) is a new patient-reported measure designed to evaluate pain-related fear and kinesiophobia in patients with painful medical conditions. It consists of 20 items that are scored on a 5-point scale. ${ }^{44}$

2. The Pain Catastrophising Scale (PCS) will be included to assess catastrophic thinking about pain. It consists of 13 items describing different thoughts and feelings that individuals may have when experiencing pain. Items are scored on a 5-point scale. A general score and scores on three subscales (ie, helplessness, magnification and rumination) will be obtained; higher scores indicate more severe catastrophic thoughts about pain. ${ }^{45}$

3. The Hospital Anxiety and Depression Scale (HADS) is a 14-item scale designed to detect anxiety and depression, independent of somatic symptoms. It consists of two 7-item subscales measuring depression (HADS-D) and anxiety (HADS-A). It uses a 4-point response scale that ranges from 0 (absence of symptoms) to 3 (maximum symptoms), with possible scores for each subscale ranging from 0 to $21 .^{46}$ Higher scores indicate higher levels of disorder. The HADS has been widely used as a screening instrument for the detection of comorbid depressive and anxiety disorders in patients with musculoskeletal disorders. ${ }^{47-49}$

4. Patient expectations of recovery will be measured by asking the participants to rate the likelihood that they would resume some form of recovery at 3, 6 and 12 months' follow-up ("How likely is it that within the next 3 months you will have resumed some form of recovery?"). Participants will indicate their response on a scale with the end points $(0 \%)$ not at all likely to $(100 \%)$ extremely likely. ${ }^{50}$

\section{Other potential prognostic factors}

1. Side of shoulder problem (right, left and both) will be coded into three levels: (i) right; (ii) left and (iii) both. 
2. Shoulder dominance (right, left and ambidexterity) will be coded into three levels: (i) right; (ii) left and (iii) ambidexterity.

3. History of previous shoulder problems will be measured with a yes/no question.

4. Current treatment will be evaluated through a checklist divided in five groups: (i) no treatment; (ii) pharmacological treatment; (iii) injections; (iv) physical therapy and (v) other treatments (massage, reflexology, acupuncture).

5. Being convinced of this pathology will be measured with a yes/no question.

6. Active shoulder ROM-free of pain will be measured with a manual inclinometer placed in the affected shoulder.

7. Comorbidities will be tested with the Self-Administered Comorbidity Questionnaire (SCQ).$^{51}$ Patients will be asked if they had one or more medical conditions (from a list of 15 diagnoses). If they gave a positive response, they will be asked whether the condition limited their activity.

8. Recurrence of shoulder problem was dichotomised to those patients who had a recurrent episode within the past 12 weeks and those who had a recurrent episode more than 12 weeks. With a simple answer: yes/no.

9. The Numerical Rating Scale (NRS) was used to assess each patient's pain intensity at baseline and follow-ups. The NRS scores range from 0 to 10, with 0 representing no pain and 10 representing the worst pain imaginable. The NRS has been shown to have good same-day test-retest reliability. ${ }^{52}$

10. Work status will be coded into five categories of work: (i) unemployment; (ii) sick leave; (iii) retirement; (iv) housewife and (v) active worker.

11. Work absenteeism will be measured by the following sentence: how many days (if any) within the previous 4 weeks' care workers had not attended work due to feeling ill and unfit for work. Respondents answered by number of days. Numbers were then grouped into three categories $(0=0$ days, $1=1-2$ days, $2=3$ or more days).$^{53}$

12. Work performance will be measured by the Word Health Organization Health and Work Performance Questionnaire (HPQ) through the following sentence: How would you rate your overall job performance on the days you worked during the past 4 weeks (28 days)?; responses used a scale ranging from 0 to 10 , with higher scores indicating higher work performance in the previous 4 weeks. ${ }^{54}$

13. Educational level will be coded into five educational levels: (i) university/college $\geq 4$ years; (ii) university/college 4 years; (iii) upper secondary; (iv) elementary secondary and (v) no studies. ${ }^{55}$

14. Gender, age, height and weight will be reported by self-reported questionnaire.

The summary of potential prognostic factors and outcome measures is presented in table 1 .

\section{Sample size estimation}

To contrast the null hypothesis that six potential prognostic factors (kinesiophobia, pain-related fear, pain catastrophising, anxiety-depression, age and gender) included in the estimation does not explain the primary outcome, ANOVA-test in a multiple linear regression model will be used, considering a significance level of 0.05 , and a statistical power of 0.9 , assuming that one variable (anxiety-depression ${ }^{34}$ ) provides a coefficient of determination of 0.31 , and for a higher coefficient of 0.36 , a sample of 230 patients will be needed. Assuming an expected drop-out rate of $25 \%$, a total number of 307 patients will be needed.

\section{Statistical analysis}

Data set will be carried out using SPSS for Windows (V.22; SPSS, Chicago, IL). There will be four measurements in the study, $\mathrm{T} 1=$ at baseline, $\mathrm{T} 2=3$ months, T3=6 months, T4=12 months' follow-up. KolmogorovSmirnov test will be used to analyse the normal distribution of the variables $(p>0.05)$. Continuous variables will be presented through centrality measures (mean, median), and dispersion (SD and IQR), and categorical variables through frequencies and percentages. Rank sums, Wilcoxon signed Rank test, Mann-Whitney U test and Friedman's test will be used depending on the comparisons to be made, in case of non-normal distribution of variables. For the identification of potential prognostic factors, the psychological variables (kinesiophobia, pain-related fear, pain catastrophising, anxiety, depression and patient expectations of recovery) and sociodemographic characteristics (age, gender, height, weight, shoulder problems, work status, work absenteeism, work performance, intensity of pain, active shoulder ROM-free of pain, educational level, treatments received and comorbidities) will be introduced as predictors in a multiple linear regression analysis, taking SPADI as continuous dependent variable.

Finally, analysis through COX regression will be conducted to determine the HRs of the aforementioned factors with the presence of pain and disability (using SPADI values to determine this state), through proportional hazard models. A p-value $<0.05$ will be considered statistically significant.

\section{Data collection and management}

To ensure accurate, complete and reliable data, all studyrelated information will be stored securely at the study site. All participant information will be stored in locked file cabinets in areas with limited access. A coded ID number will identify reports, data collection, process and administrative forms only to maintain participant confidentiality.

\section{Modification of the protocol}

Any modifications to the protocol that may affect the conduct of the study, potential benefit of the patient or may affect patient safety, including changes of study 


\begin{tabular}{|c|c|c|c|c|c|c|}
\hline Construct & Type & $\begin{array}{l}\text { Staff } \\
\text { member }\end{array}$ & $\begin{array}{l}\text { Baseline } \\
\text { (T1) }\end{array}$ & $\begin{array}{l}3 \text { months } \\
\text { (T2) }\end{array}$ & $\begin{array}{l}6 \text { months } \\
\text { (T3) }\end{array}$ & $\begin{array}{l}12 \text { months } \\
\text { (T4) }\end{array}$ \\
\hline \multicolumn{7}{|l|}{ Outcome measures } \\
\hline Pain and function & SPADI & Interviewer & $\mathrm{X}$ & $x$ & $\mathrm{X}$ & $\mathrm{X}$ \\
\hline Self-efficacy & PSEQ & Interviewer & $\mathrm{X}$ & $\mathrm{X}$ & $\mathrm{X}$ & $\mathrm{X}$ \\
\hline \multicolumn{7}{|l|}{ Shoulder problems } \\
\hline Side of shoulder problem (i) right; (ii) left; (iii) both. & $\begin{array}{l}\text { Self-reported } \\
\text { questionnaire }\end{array}$ & Interviewer & $\mathrm{X}$ & & & \\
\hline Shoulder dominance (i) right; (ii) left; (iii) ambidexterity & $\begin{array}{l}\text { Self-reported } \\
\text { questionnaire }\end{array}$ & Interviewer & $\mathrm{x}$ & & & \\
\hline History of previous shoulder problems & $\begin{array}{l}\text { Self-reported } \\
\text { questionnaire } \\
\text { (yes/no) }\end{array}$ & Interviewer & $x$ & & & \\
\hline $\begin{array}{l}\text { What modality of treatment? ((i) no treatment; (ii) pharmacological } \\
\text { treatment; (iii) injections; (iv) physical therapy; (v) other treatments } \\
\text { (massage, reflexology, acupuncture) }\end{array}$ & $\begin{array}{l}\text { Self-reported } \\
\text { questionnaire }\end{array}$ & Interviewer & $\mathrm{X}$ & $\mathrm{X}$ & $\mathrm{X}$ & $\mathrm{X}$ \\
\hline Have you been convinced of this pathology? & $\begin{array}{l}\text { Self-reported } \\
\text { questionnaire } \\
\text { (yes/no) }\end{array}$ & Interviewer & $\mathrm{x}$ & $x$ & $x$ & $\mathrm{X}$ \\
\hline \multicolumn{7}{|l|}{ Potential prognostic factors } \\
\hline Pain-related fear and kinesiophobia & FACS & Interviewer & $\mathrm{X}$ & $\mathrm{X}$ & $\mathrm{X}$ & $\mathrm{X}$ \\
\hline Pain catastrophising & PSC & Interviewer & $\mathrm{X}$ & $\mathrm{X}$ & $\mathrm{X}$ & $\mathrm{X}$ \\
\hline Active shoulder ROM-free of pain & Manual Inclinometer & Interviewer & $\mathrm{X}$ & $\mathrm{X}$ & $\mathrm{X}$ & $\mathrm{X}$ \\
\hline Anxiety and depression & HADS & Interviewer & $\mathrm{X}$ & $\mathrm{X}$ & $\mathrm{X}$ & $\mathrm{X}$ \\
\hline Patient expectations of recovery & $\begin{array}{l}\text { Self-reported question } \\
(0-100)\end{array}$ & Interviewer & $\mathrm{x}$ & $\mathrm{X}$ & $x$ & $\mathrm{X}$ \\
\hline Comorbidities & $\mathrm{SCQ}$ & Interviewer & $\mathrm{X}$ & $\mathrm{X}$ & $\mathrm{X}$ & $\mathrm{X}$ \\
\hline Recurrence of shoulder pain & $\begin{array}{l}\text { Self-reported } \\
\text { questionnaire } \\
\text { (yes/no) }\end{array}$ & Interviewer & $\mathrm{X}$ & & & \\
\hline Intensity of pain & NRS & Interviewer & $\mathrm{X}$ & $\mathrm{X}$ & $\mathrm{X}$ & $\mathrm{X}$ \\
\hline $\begin{array}{l}\text { Work status ((i) unemployment; (ii) sick leave; (iii) retirement; (iv) } \\
\text { housewife; (v) active worker) }\end{array}$ & $\begin{array}{l}\text { Self-reported } \\
\text { questionnaire }\end{array}$ & Interviewer & $\mathrm{X}$ & $\mathrm{X}$ & $x$ & $\mathrm{X}$ \\
\hline Work absenteeism & $\begin{array}{l}\text { Self-reported } \\
\text { questionnaire }\end{array}$ & Interviewer & $\mathrm{X}$ & $\mathrm{x}$ & $\mathrm{x}$ & $\mathrm{X}$ \\
\hline Work performance & $\begin{array}{l}\text { Question obtaining } \\
\text { of HPQ }\end{array}$ & Interviewer & $x$ & $\mathrm{X}$ & $\mathrm{X}$ & $\mathrm{x}$ \\
\hline Age, gender & $\begin{array}{l}\text { Self-reported } \\
\text { questionnaire }\end{array}$ & Interviewer & $\mathrm{X}$ & & & \\
\hline Height, weight & $\begin{array}{l}\text { Self-reported } \\
\text { questionnaire }\end{array}$ & Interviewer & $\mathrm{X}$ & & & \\
\hline $\begin{array}{l}\text { Educational level: (i) university/college } \geq 4 \text { years; (ii) university/college } \\
4 \text { years; (iii) upper secondary; (iv) elementary secondary; (v) no studies }\end{array}$ & $\begin{array}{l}\text { Self-reported } \\
\text { questionnaire }\end{array}$ & Interviewer & $\mathrm{x}$ & & & \\
\hline
\end{tabular}


objectives, study design, patient population, sample sizes and study procedures, or significant administrative aspects will require a formal amendment to the protocol.

Such amendment will be agreed on by this research group and approved by Costa del Sol Ethics Committee, Malaga, Spain, prior to implementation and notified to the health authorities in accordance with local regulations.

\section{Dissemination}

The trial is registered in Clinicaltrials.gov: NCT02738372.

The results of the study will be disseminated at several research conferences and as published articles in peerreviewed journals.

\section{DISCUSSION}

The present study will be the first study analysing the role of a long battery of psychological factors (painrelated fear, kinesiophobia, anxiety, depression, patient expectations of recovery and pain catastrophising) in the prognosis of CSP. Previous studies ${ }^{32-34} 5657$ have evaluated the influence of several psychological factors on the prognosis of CSP. Macfarlane et a ${ }^{\tilde{6} 6}$ showed how higher levels of psychological distress predicted perpetuation of CSP. Badcock et a $\tilde{l}^{57}$ reported association between disability and psychological distress after controlling for possible confounders. Reilingh $e t a l^{22}$ exposed how higher levels of pain catastrophising predicted recurrence of symptoms in CSP. Gill $e t a l^{33}$ showed how recurrent shoulder pain was associated with depressive symptoms. Chester $e t a l^{34}$ reported how higher patient expectation of complete recovery compared to slight improvement as a result of physiotherapy and higher pain self-efficacy were associated with patient-rated outcomes. These previous studies support the necessity of carrying out the present study, but also the inclusion of several psychological factors, which have not been already evaluated on the prognosis of CSP, such as painrelated fear, kinesiophobia and anxiety, justifying the development of this cohort study, because it seems presumable that psychological factors may play an essential role along with biomedical and/or biomechanical factors in the perpetuation of chronicity in patients with CSP. Besides that, this will be the first study evaluating self-efficacy as an outcome measure in shoulder region. Previous studies have explored how psychological factors influence self-efficacy in chronic musculoskeletal conditions, ${ }^{58}$ and how several therapeutic strategies could improve this psychological construct. ${ }^{59} 60$ Therefore, the inclusion of self-efficacy as an outcome in this study could be reasonable, because this construct is based on how a person's perceived confidence in the ability of successfully carrying out daily and/or work activities or behaviour despite the pain, ${ }^{61}$ and people with CSP usually have to do many tasks that implicate the movement of their shoulders. That is why, detecting possible factors which contribute to improve or reducing effects of self-efficacy in people with CSP may give rise to benefits for this population.

\section{Strengths and weaknesses of the study}

The strengths of this study will include a long battery of psychological factors evaluating their role in the prognosis of CSP, the exploration of the mediating power of self-efficacy, kinesiophobia and pain catastrophising in CSP, the inclusion of self-efficacy as an outcome measure and the use of the SPIRIT checklist to give more quality to the study. The limitations associated with this study must be acknowledged when interpreting the results. First, information bias could be an important limitation of this study. Some participants may have problems to deal with the questionnaires and remember any situation associated with their pain and disability at 3, 6 and 12 months' follow-up. Even so, some participants might be more likely to deny participation or abort follow-up. However, adding a drop-out rate of $20 \%$ in sample size calculation should alleviate this risk. Furthermore, some psychological factors such as pain acceptance and psychological distress will be not included in this study, because it takes too much time to carry out all the self-reported questionnaires, and participants may not respond clearly. Another limitation could be that some psychological factors are quite broad in definition, increasing the risk on finding conflicting evidence on their relationship with outcomes.

\section{Clinical and research implications of study findings}

The early identification of which psychological factors have higher predictive value in people with CSP may assist clinicians in decision-making, and timely and specific consultations with-or referral to-other healthcare providers, and to researchers in exploring which psychological factors could be the most predictive power in shoulder region, giving rise to the possibility to steer treatments. That is why clinicians should be encouraged to identify patients with CSP who show psychological symptoms in the preliminary assessment, as this approach might increase the possibility to consider other therapeutic interventions rather than physical therapies for CSP, for example, pain neuroscience education.

\section{Future research}

Further studies analysing prospectively the influence of psychological factors on the prognosis of CSP including several factors such as pain acceptance, psychological distress and/or coping with pain are needed. As CSP is a complex multifactorial condition, future investigations should consider the combination, and interaction of a cluster of factors to increase their predictive value, and to determine the importance of each factor. Even though the effect caused by psychological factors on the prognosis of CSP could be relevant, further research 
evaluating the effects of these factors on the prognosis of CSP, and the possible mediating power of these factors in this entity, as well as their clinical usefulness is required.

\section{CONCLUSION}

Despite the neuroanatomical and biomechanical basis of shoulder pain is interminable and not completely understood, this prospective cohort study may contribute to a new vision about the role played by pain-related fear, kinesiophobia, anxiety, depression and pain catastrophising in the prognosis of CSP, and how self-efficacy, kinesiophobia and pain catastrophising mediate the relationship between symptoms, increasing the body of knowledge in this field.

\section{Current study status}

The recruitment of patients began in August 2016.

\section{Author affiliations}

${ }^{1}$ Department of Physiotherapy, University of Malaga, Malaga, Spain ${ }^{2}$ Rehabilitation Sciences and Physiotherapy Department, University of Antwerp, Antwerp, Belgium

${ }^{3}$ Rehabilitation Sciences and Physiotherapy Department, Ghent University, Ghent, Belgium

${ }^{4}$ Pain in Motion International Research Group, Ghent, Belgium

${ }^{5}$ Department of Nursing, University of Malaga, Malaga, Spain

Contributors AL-S conceived the study. AL-S and JM-C initiated the study design and FS and MM helped with the final version of this protocol. AL-S and FS provided statistical expertise in longitudinal trial design and JMM-A will be conducting the primary statistical analysis. All authors contributed to the refinement of the study protocol and approved the final manuscript.

Funding This study is supported by University of Malaga, Spain.

Disclaimer The funding source has no role in study design, in data collection, analysis and interpretation, in the writing of the report or in the decision to submit the paper for publication.

Competing interests None declared.

Provenance and peer review Not commissioned; externally peer reviewed.

Open Access This is an Open Access article distributed in accordance with the Creative Commons Attribution Non Commercial (CC BY-NC 4.0) license, which permits others to distribute, remix, adapt, build upon this work noncommercially, and license their derivative works on different terms, provided the original work is properly cited and the use is non-commercial. See: http:// creativecommons.org/licenses/by-nc/4.0/

\section{REFERENCES}

1. Klintberg $\mathrm{IH}$, Cools $\mathrm{AM}$, Holmgren TM, et al. Consensus for physiotherapy for shoulder pain. Int Orthop 2015;39:715-20.

2. Urwin M, Symmons D, Allison T, et al. Estimating the burden of musculoskeletal disorders in the community: the comparative prevalence of symptoms at different anatomical sites, and the relation to social deprivation. Ann Rheum Dis 1998;57:649-55.

3. Green S, Buchbinder R, Hetrick S. Physiotherapy interventions for shoulder pain. Cochrane Database Syst Rev 2003;(2):CD004258.

4. House J, Mooradian A. Evaluation and management of shoulder pain in primary care clinics. South Med J 2010;103:1129-35. doi:10.1097/SMJ.0b013e3181f5e85f

5. Eriksen W. The prevalence of musculoskeletal pain in Norwegian nurses' aides. Int Arch Occup Environ Health 2003;76:625-30.

6. Roquelaure $\mathrm{Y}, \mathrm{Ha} \mathrm{C}$, Leclerc $\mathrm{A}$, et al. Epidemiologic surveillance of upper-extremity musculoskeletal disorders in the working population Arthritis Care Res 2006;55:765-78.
7. Chard MD, Hazleman R, Hazleman BL, et al. Shoulder disorders in the elderly: a community survey. Arthritis Rheum 1991;34: 766-9.

8. Walker-Bone K, Palmer KT, Reading I, et al. Prevalence and impact of musculoskeletal disorders of the upper limb in the general population. Arthritis Rheum 2004;51:642-51.

9. Van der Heijden GJ. Shoulder disorders: a state-of-the-art review. Baillieres Best Pract Res Clin Rheumatol 1999;13:287-309.

10. Picavet HS, Schouten JS. Musculoskeletal pain in the Netherlands: prevalences, consequences and risk groups, the DMC3-study. Pain 2003;102:167-78.

11. van der Windt DA, Koes BW, Boeke AJ, et al. Shoulder disorders in general practice: prognostic indicators of outcome. $\mathrm{Br} J \mathrm{Gen} \mathrm{Pr}$ 1996;46:519-23.

12. Bot SD, van der Waal JM, Terwee CB, et al. Incidence and prevalence of complaints of the neck and upper extremity in general practice. Ann Rheum Dis 2005;64:118-23.

13. Feleus A, Bierma-Zeinstra SM, Miedema HS, et al. Incidence of non-traumatic complaints of arm, neck and shoulder in general practice. Man Ther 2008;13:426-33.

14. Linsell L, Dawson J, Zondervan K, et al. Prevalence and incidence of adults consulting for shoulder conditions in UK primary care; patterns of diagnosis and referral. Rheumatology (Oxford) 2006;45:215-21.

15. Luime JJ, Koes BW, Hendriksen IJ, et al. Prevalence and incidence of shoulder pain in the general population; a systematic review. Scand J Rheumatol 2004;33:73-81.

16. Greving K, Dorrestijn O, Winters JC, et al. Incidence, prevalence, and consultation rates of shoulder complaints in general practice. Scand J Rheumatol 2012;41:150-5.

17. Bergman $\mathrm{S}$, Herrström $\mathrm{P}$, Högström $\mathrm{K}$, et al. Chronic musculoskeletal pain, prevalence rates, and sociodemographic associations in a Swedish Population Study. J Rheumatol 2001;28:1369-77.

18. McBeth J, Jones K. Epidemiology of chronic musculoskeletal pain. Best Pract Res Clin Rheumatol 2007;21:403-25.

19. Croft P, Pope D, Silman A. The clinical course of shoulder pain: prospective cohort study in primary care. Primary Care Rheumatology Society Shoulder Study Group. BMJ 1996;313:601-2. https://doi.org/10.1136/bmj.313.7057.601

20. Luime JJ, Koes BW, Miedem HS, et al. High incidence and recurrence of shoulder and neck pain in nursing home employees was demonstrated during a 2-year follow-up. J Clin Epidemio 2005;58:407-13.

21. Smith KL, Harryman DT II, Antoniou J, et al. A prospective, multipractice study of shoulder function and health status in patients with documented rotator cuff tears. J Shoulder Elb Surg 2000;9:395-402.

22. Roquelaure $\mathrm{Y}$, Mariel J, Fanello S, et al. Active epidemiological surveillance of musculoskeletal disorders in a shoe factory. Occup Environ Med 2002;59:452-8.

23. Greenberg DL. Evaluation and treatment of shoulder pain. Med Clin North Am 2014;98:487-504.

24. van den Dolder PA, Ferreira PH, Refshauge KM. Effectiveness of soft tissue massage and exercise for the treatment of non-specific shoulder pain: a systematic review with meta-analysis. $\mathrm{Br} J$ Sports Med 2014;48:1216-26.

25. Nijs J, Goubert D, Ickmans K. Recognition and treatment of central sensitization in chronic pain patients: not limited to specialized care. J Orthop Sport Phys Ther 2016;46:1024-8.

26. Dean BJ, Gwilym SE, Carr AJ. Why does my shoulder hurt? A review of the neuroanatomical and biochemical basis of shoulder pain. Br J Sports Med 2013;47:1095-104.

27. Turk DC, Okifuji A. Psychological factors in chronic pain: evolution and revolution. J Consult Clin Psychol 2002;70: 678-90.

28. Diatchenko L, Fillingim RB, Smith SB, et al. The phenotypic and genetic signatures of common musculoskeletal pain conditions. Nat Rev Rheumatol 2013:9:340-50.

29. Thompson E, Broadbent J, Bertino MD, et al. Do Pain-related beliefs influence treatment adherence? A Systematic Review. Clin J Pain 2015;32:1.

30. Rajapakse D, Liossi C, Howard RF. Presentation and management of chronic pain. Arch Dis Child 2014;99:474-80.

31. Jensen MP, Ward LC, Thorn BE, et al. Measuring the cognitions, emotions, and motivation associated with avoidance behaviors in the context of pain: preliminary development of the negative responsivity to pain scales. Clin J Pain 2016. Published Online First.

32. Reilingh ML, Kuijpers T, Tanja-Harfterkamp AM, et al. Course and prognosis of shoulder symptoms in general practice. Rheumatology (Oxford) 2008;47:724-30. 
33. Gill TK, Shanahan EM, Taylor AW, et al. Shoulder pain in the community: an examination of associative factors using a longitudinal cohort study. Arthritis Care Res 2013;65:2000-7.

34. Chester R, Jerosch-Herold C, Lewis J, et al. Psychological factors are associated with the outcome of physiotherapy for people with shoulder pain: a multicentre longitudinal cohort study. $\mathrm{Br} J$ Sport Med 2016.

35. Asghari A, Nicholas MK. Pain self-efficacy and pain behaviour. A prospective study. Pain 2001;94:85-100.

36. Van Liew C, Brown KC, Cronan TA, et al. Predictors of pain and functioning over time in fibromyalgia syndrome: an autoregressive path analysis. Arthritis Care Res (Hoboken) 2013;65:251-6.

37. Woby SR, Urmston M, Watson PJ. Self-efficacy mediates the relation between pain-related fear and outcome in chronic low back pain patients. Eur J Pain 2007;11:711-8.

38. Costa Lda C, Maher CG, McAuley JH, et al. Self-efficacy is more important than fear of movement in mediating the relationship between pain and disability in chronic low back pain. Eur J Pain 2011;15:213-9.

39. Skidmore JR, Koenig AL, Dyson SJ, et al. Pain self-efficacy mediates the relationship between depressive symptoms and pain severity. Clin J Pain 2015;31:137-44.

40. Kooijman MK, Barten DJ, Swinkels IC, et al. Pain intensity, neck pain and longer duration of complaints predict poorer outcome in patients with shoulder pain-a systematic review. BMC Musculoskelet Disord 2015;16:288.

41. McClure PW, Michener LA. Staged approach for rehabilitation classification: shoulder disorders (STAR-Shoulder). Phys Ther 2015;95:791-800.

42. Luque-Suarez A, Rondon-Ramos A, Fernandez-Sanchez M, et al. Spanish version of SPADI (shoulder pain and disability index) in musculoskeletal shoulder pain: a new 10-items version after confirmatory factor analysis. Health Qual Life Outcomes 2016;14:32

43. Nicholas MK. The pain self-efficacy questionnaire: taking pain into account. Eur J Pain 2007;11:153-63.

44. Neblett R, Mayer TG, Hartzell MM, et al. The Fear-avoidance Components Scale (FACS): development and psychometric evaluation of a new measure of pain-related fear avoidance. Pain Pract 2016;16:435-50.

45. Sullivan MJL, Bishop SR, Pivik J. The pain catastrophizing scale: development and validation. Psychol Assess 1995;7:524-32.

46. Kori SH, Miller RP, Todd DD. Kinesiophobia: a new view of chronic pain behaviour. Pain Manag 1990;3:35-43.

47. Pallant JF, Bailey CM. Assessment of the structure of the Hospital Anxiety and Depression Scale in musculoskeletal patients. Heal Qual Life Outcomes 2005;3:82.
48. Härter M, Reuter K, Gross-Hardt K, et al. Screening for anxiety, depressive and somatoform disorders in rehabilitation-validity of HADS and GHQ-12 in patients with musculoskeletal disease. Disabil Rehabil 2001;23:737-44.

49. Cho $\mathrm{CH}$, Jung SW, Park JY, et al. Is shoulder pain for three months or longer correlated with depression, anxiety, and sleep disturbance? J Shoulder Elb Surg 2013;22:222-8.

50. Carriere JS, Thibault $\mathrm{P}$, Milioto $\mathrm{M}$, et al. Expectancies mediate the relations among pain catastrophizing, fear of movement, and return to work outcomes after Whiplash injury. J Pain 2015;16:1280-7.

51. Sangha O, Stucki G, Liang MH, et al. The Self-Administered Comorbidity Questionnaire: a new method to assess comorbidity for clinical and health services research. Arthritis Rheum 2003;49:156-63.

52. Downie WW, Leatham PA, Rhind VM, et al. Studies with pain rating scales. Ann Rheum Dis 1978;37:378-81.

53. Aronsson G, Gustafsson K, Dallner M. Sick but yet at work. An empirical study of sickness presenteeism. J Epidemiol Community Heal 2000;54:502-9.

54. Kessler RC, Barber C, Beck A, et al. The World Health Organization Health and Work Performance Questionnaire (HPQ). J Occup Env Med 2003;45:156-74.

55. Sterud T, Johannessen HA, Tynes T. Do work-related mechanical and psychosocial factors contribute to the social gradient in low back pain?: a 3-year follow-up study of the general working population in Norway. Spine 2016;41:1089-95.

56. Macfarlane GJ, Hunt IM, Silman AJ. Predictors of chronic shoulder pain: a population based prospective study. J Rheumatol 1998;25:1612-5.

57. Badcock LJ, Lewis M, Hay EM, et al. Chronic shoulder pain in the community: a syndrome of disability or distress?. Ann Rheum Dis 2002;61:128-31.

58. Rahman A, Reed E, Underwood M, et al. Factors affecting self-efficacy and pain intensity in patients with chronic musculoskeletal pain seen in a specialist rheumatology pain clinic. Rheumatology (Oxford) 2008;47:1803-8.

59. Damush TM, Kroenke K, Bair MJ, et al. Pain self-management training increases self-efficacy, self-management behaviours and pain and depression outcomes. Eur J Pain 2016;20:1070-8.

60. Ludvigsson ML, Peterson G, Dedering $\AA$, et al. One- and two-year follow-up of a randomized trial of neck-specific exercise with or without a behavioural approach compared with prescription of physical activity in chronic whiplash disorder. J Rehabil Med 2016;48:56-64.

61. Bandura A. Self-efficacy: toward a unifying theory of behavioral change. Psychol Rev 1977;84:191-215. 